Artículo

\title{
Cambios fisiológicos en árboles de limón mexicano en producción infectados con HLB
}

\author{
Miguel Ángel Manzanilla-Ramírez ${ }^{1}$ \\ Ángel Villegas-Monter ${ }^{1 \S}$ \\ José Joaquín Velázquez-Monreal ${ }^{2}$ \\ Hilda Araceli Zavaleta-Mancera ${ }^{1}$ \\ Manuel Sandoval-Villa ${ }^{1}$ \\ Abel Muñoz-Orozco ${ }^{1}$ \\ ${ }^{1}$ Posgrado en Fisiología Vegetal-Colegio de Postgraduados. Carretera México-Texcoco km 36.5, \\ Montecillo, Estado de México. CP. 562302. (manzanilla.miguel@colpos.mx; zavaleta@colpos.mx; \\ smanuel@colpos.mx; amunoz@colpos.mx). ${ }^{2}$ Campo Experimental Tecomán-INIFAP. Carretera Colima- \\ Manzanillo km 35, Tecomán, Colima, México. \\ ${ }^{\S}$ Autor para correspondencia: avillega@colpos.mx.
}

\section{Resumen}

El huanglongbing (HLB) es la enfermedad más devastadora de los cítricos a nivel mundial y está presente en el estado de Colima desde 2010, zona productora de limón mexicano (Citrus aurantifolia). Esta enfermedad causa un desequilibrio en el reparto de carbohidratos e inhibe la fotosíntesis. También afecta la concentración de nutrientes en hoja. El objetivo de este trabajo fue determinar los cambios fisiológicos en árboles en producción de limón mexicano infectados con HLB. El estudio se desarrolló en Colima en 2017. Se determinó la concentración de almidón, sacarosa y glucosa en nervadura central y lámina de hojas de diferentes edades (120 y 30 días) y almidón en raíces. La concentración de clorofilas por método analítico e índice SPAD en hojas con diferentes niveles de síntomas de HLB y análisis foliares de nutrientes minerales. Las hojas con HLB tuvieron mayor concentración de almidón en la lámina de 120 días. La sacarosa se concentró en las nervaduras de hojas de 120 días. Mientras que la glucosa se incrementó en las nervaduras de 30 y 120 días. Las raíces de árboles infectados con HLB mostraron 40\% menor concentración de almidón comparados con árboles sanos. Disminución en el contenido de clorofilas e índice SPAD en función del grado de afectación. Así como menor concentración de $\mathrm{K}, \mathrm{Ca}, \mathrm{Mg}, \mathrm{Cu}, \mathrm{Fe}, \mathrm{Zn}$ y $\mathrm{B}$. El conocer los cambios que ocasiona el HLB en limón mexicano permitirá desarrollar prácticas que disminuyan su impacto.

Palabras clave: Citrus aurantifolia, azúcares, clorofila, huanglongbing.

Recibido: agosto de 2019

Aceptado: octubre de 2019 


\section{Introducción}

El huanglongbing (HLB) En México, se han asociado a la presencia de la $\alpha$-proteobacteria 'Candidatus Liberibacter asiáticus' (CLas), conocido comúnmente en la región del pacifico de México como dragón amarillo, es la enfermedad más devastadora de los cítricos, que afecta a todas las especies y variedades cultivadas en el mundo (Bové, 2006). El HLB es una de las enfermedades más complejas, debido a las interacciones entre el patógeno, vector, hospederos y ambiente (da Graça et al., 2015). No existen reportes de alguna cura para los árboles infectados con HLB, los que en poco tiempo se vuelven decadentes y poco productivos (Bové, 2006).

En cítricos los primeros síntomas visibles asociados al HLB son el amarillamiento de las nervaduras en las hojas maduras y el moteado asimétrico difuso (Cimo et al., 2013), que se presenta debido a la alta acumulación de almidones y la desintegración del sistema tilacoide del cloroplasto en las hojas maduras (Etxeberria et al., 2009; Gonzalez et al., 2011). Estos patrones cloróticos son semejantes a las deficiencias de minerales como zinc, hierro y manganeso lo cual puede complican el diagnóstico (Etxeberria et al., 2009; Spann y Schumann, 2009; Spann et al., 2011). Estos moteados también son resultado de la baja absorción de agua debido a la pérdida de raíces por la falta de carbohidratos (Jagoueix et al., 1994; Spann et al., 2011; Cimo et al., 2013).

El HLB causa desequilibrios metabólicos en el huésped por agotamiento de nutrientes y interferencia del transporte (Duan et al., 2009). Lo que tiene como consecuencia disminución de la producción, el cual es el síntoma más impactante en las áreas productoras de cítricos del mundo (Bové, 2006; Li et al., 2009; González et al., 2012). En 2010 se detectó HLB en la zona productora de limón mexicano (Citrus aurantifolia) en el estado de Colima. A partir, de su presencia se ha registrado disminución de 50\% de la producción (Robles-González et al., 2013; Robles-González et al., 2017).

Esta disminución provocó la caída del empleo, generando problemas sociales y deprimiendo la demanda de bienes y servicios en las zonas productoras de limón mexicano (Avalos y González, 2013). Los síntomas de esta enfermedad en México están asociados a la presencia de CLas, que es un parásito obligado, restringida al floema y que es diseminada eficientemente por el psílido asiático de los cítricos (Diaphorina citri) cuando se alimenta del floema, esta bacteria una vez dentro del árbol libera salicilato de metilo un químico volátil específico, que atrae a la población de insectos vectores para alimentarse del árbol infectado y así, es como el patógeno ingresa a mayor número de insectos, también CLas puede transmitirse de plantas de cítricos enfermas a sanas mediante injertos (Mann et al., 2012; Munir et al., 2017).

En limón mexicano se han registrado la disminución de la producción desde etapas tempranas de la infección hasta más del $50 \%$ en árboles que presentan síntomas en más de $75 \%$ de su copa, también se reportó disminución en el tamaño de la fruta cosechada (Robles-González et al., 2013; Robles-González et al., 2017). En Colima también se ha reportaron la presencia de Candidatus Phytoplasma asteris (CPa) junto con CLas (Arratia-Castro et al., 2014; Arratia-Castro et al., 2016) en árboles de limón mexicano que mostraban los mismos síntomas de Huanglongbing (HLB). Los síntomas en hojas de limón mexicano incluyen puntos cloróticos, manchas angulares, acorchamiento y engrosamiento de nervaduras, moteado y clorosis difusa hasta el amarillamiento generalizado en la lámina foliar y defoliación. 
Se ha observado maduración irregular de frutos, la cual inicia con amarillento en la parte basal y eventualmente termina en la caída de frutos (Robles-González et al., 2017). Histológicamente existe incremento de almidón en el mesófilo de la hoja y se presenta hiperplasia, lo que ocasiona colapso de floema (Esquivel-Chávez et al., 2012). La distribución del patógeno no es uniforme, y se ha encontrado la mayor concentración de bacterias en las nervaduras y brotes (Li et al., 2006).

Una vez dentro de la planta CLas migra hacia el floema ocasionando la formación y acumulación de tapones de calosa en los tubos cribosos (Da Graça y Korsten, 2004; Koh et al., 2012). El bloqueo del floema ocasiona la acumulación de almidón en los órganos fuente y agotamiento en los órganos demanda o de almacenamiento (Etxeberria et al., 2009; Rosales y Burns, 2011).

Afectando el transporte de nutrientes y colapso celular (Garnier y Bové, 1996; Bové, 2006; Kim et al., 2009; Cimo et al., 2013) sufriendo daño en las raíces debido a la interrupción del transporte de fotosintatos de los brotes hacia la raíz, como consecuencia las raíces están poco desarrolladas y el crecimiento es suprimido (Etxeberria et al., 2009; Cimo et al., 2013) pueden también infectarse con patógenos secundarios (Pereira y Milori, 2010).

Por lo tanto, los minerales y el agua que son transportados de la raíz a los brotes decrece (Zhang et al., 2011). Otro síntoma presente es la muerte regresiva de ramillas y ramas, registrándose disminución en la producción (Etxeberria et al., 2009; Cimo et al., 2013). A medida que se incrementa el tiempo de la infección de HLB, aumentan las deficiencias de nutrientes y desequilibrios de carbohidratos en hojas y raíces (Etxeberria et al., 2009; Rosales y Burns, 2011), deteniendo el desarrollo de las plantas y finalmente puede llegar la muerte.

La infección por HLB tiene diferentes impactos en la reabsorción de nutrientes en función del genotipo. Por lo que mantener eficiente el ciclo de nutrientes interno puede ser una estrategia de las especies de cítricos tolerantes al HLB (Cao et al., 2015). El presente trabajo tiene como objetivo determinar los cambios fisiológicos de hojas y raíces de árboles en producción de limón mexicano variedad Colimex infectadas con HLB. Debido a que la identificación de las respuestas del huésped al patógeno es crítica para comprender el desarrollo de la enfermedad y puede ser utilizada en la formulación de prácticas eficientes de manejo.

\section{Materiales y métodos}

La investigación se realizó de abril a junio de 2017 en la zona productora de limón mexicano de Tecomán, Colima, México, caracterizada por tener clima tropical seco y semiseco, con temperatura media de $26{ }^{\circ} \mathrm{C}$ y precipitación media de $750 \mathrm{~mm}$. Se utilizó la variedad de limón mexicano "Colimex" injertada en Macrofila (Citrus macrophylla) con 5 años de edad debido a que esta combinación es la más utilizada en las zonas productoras de este cítrico. Los árboles con HLB se inocularon por injerto de púa y se corroboraron por PCR. Las plantas sanas y con HLB se establecieron en abril de 2012.

En contenedores con capacidad 60 litros, densidad de 2 × $3 \mathrm{~m}$. El sustrato compuesto de 1:1:1 (V/V/V partes de polvillo de coco, tierra y lombricomposta). El resto de las labores de cultivo se realizaron de acuerdo al paquete tecnológico recomendado por el INIFAP (Manzanilla, 2018). Este estudio se desarrolló dentro de una estructura de malla antiáfidos de $250 \mathrm{~m}^{2}$ en las instalaciones 
del Campo Experimental Tecomán del INIFAP. Se evaluaron dos tratamientos árboles infectados con HLB y árboles sanos. Se utilizó un diseño experimental completamente al azar. La parcela experimental se conformó de 8 árboles por tratamiento.

\section{Concentración de carbohidratos en diferentes tejidos de limón mexicano}

Para evaluar las concentraciones de almidón, se seleccionaron hoja y raíces de árboles con HLB y árboles sanos. De cincuenta hojas por tratamiento se separaron nervaduras y lamina foliar de hojas maduras (120 días) y hojas inmaduras (30 días). También se evaluó el contenido de almidón en raíces secundarias.

La extracción de almidón se realizó de forma separada para hoja y raíz a partir de $20 \mathrm{mg}$ de tejidos liofilizado y molido de cada muestra. Se le adicionó $500 \mu \mathrm{L}$ de agua destilada y se incubó a 100 ${ }^{\circ} \mathrm{C}$ por 10 min. Posteriormente, la mezcla se centrifugó a $10774 \mathrm{rpm}$ por $2 \mathrm{~min}$. Se recuperó 300 $\mu \mathrm{L}$ de sobrenadante en un tubo eppendorf y se le adicionó $900 \mu \mathrm{L}$ de alcohol puro y se centrifugó a $9449 \mathrm{rpm}$ por $5 \mathrm{~min}$.

Se desechó el sobrenadante y el almidón precipitado se resuspendió en $1 \mathrm{~mL}$ de agua bidestilada estéril (Milli-Q) y se agitó en un vortex por 3 min (González et al., 2011). Para la cuantificación de almidón, se adicionó $30 \mu 0 \mathrm{~L}$ del extracto de almidón y $50 \mu \mathrm{L}$ de solución de yodo a una placa óptica de 96 pozos y se leyó la absorbancia a $595 \mathrm{~nm}$ por triplicado en un espectrofotómetro (Thermo Scientific ${ }^{\mathrm{TM}}$ Multiskan GO, USA). Se elaboró una curva estándar a partir de almidón de arroz puro (Sigma-Aldrich, USA).

Debido a que las principales azucares presente en el floema de los cítricos son sacarosa y glucosa con 64 y 20\% respectivamente (Hijaz y Killiny, 2014). Se determinaron las concentraciones de estos en tejidos de hoja en nervadura y lamina foliar de 120 y 30 días. Cuantificados con kits comerciales (Sigma-Aldrich, USA).

\section{Concentración de clorofila en hojas}

Se determinó la concentración de clorofila en hojas de limón mexicano con diferentes grados afectación por HLB (Figura 1). Se eligieron 5 estados de desarrollo de la enfermedad en hojas maduras y se cuantifico la clorofila a, clorofila b y clorofila total de acuerdo con (Warren, 2008).

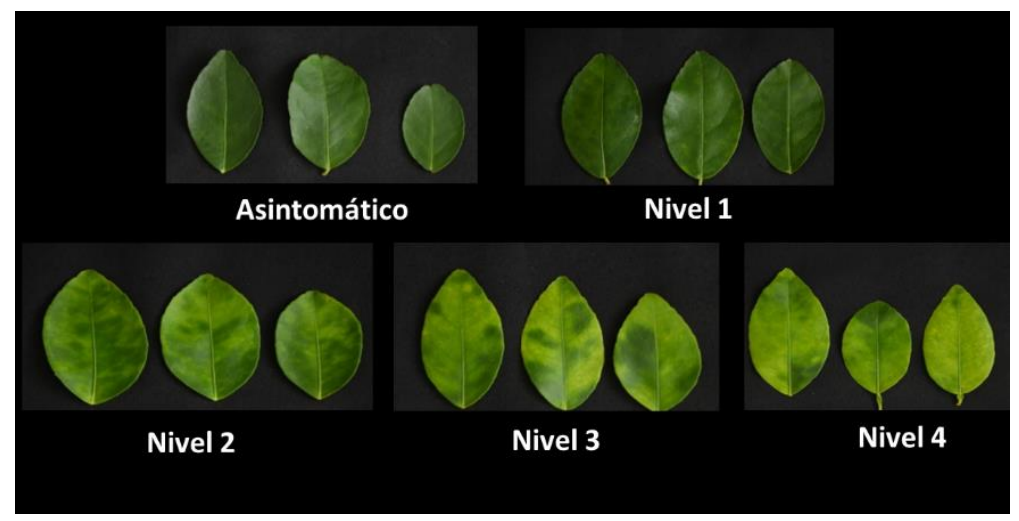

Figura 1. Niveles de síntomas de HLB en hojas de limón Colimex de árboles en producción. 
A la misma hoja se les midió el índice SPAD debido a su alta correlación con el contenido real de clorofila en las hojas (Intrigliolo et al., 2000). Las lecturas se realizaron con medidor portátil de clorofilas SPAD 502 (Soil Plant Analysis Development, Minolta).

\section{Análisis foliar de nutrimentos}

Se evaluaron las concentraciones de macro y micronutrientes en hoja maduras (120 días). Provenientes de árboles sanos y con HLB. Se colectaron 100 hojas maduras de cada tratamiento. Para cada muestra se realizó una mezcla compuesta y tres repeticiones. Las muestras se secaron en horno marca Felisa ${ }^{\circledR}$ a temperatura entre 65 a $70{ }^{\circ} \mathrm{C}$ por $72 \mathrm{~h}$. Posteriormente, se secaron a peso constante y se procesaron en molino eléctrico marca Thomas Scientific $®$, con malla de 40 cavidades, obteniendo finalmente polvo fino, el cual se usó para las digestiones.

Los elementos analizados fueron nitrógeno total $(\mathrm{N})$, fósforo $(\mathrm{P})$, potasio $(\mathrm{K})$, calcio $(\mathrm{Ca}) \mathrm{y}$ magnesio $(\mathrm{Mg})$; y los microelementos fierro $(\mathrm{Fe})$, cobre $(\mathrm{Cu})$, zinc $(\mathrm{Zn})$, manganeso $(\mathrm{Mn})$ y boro (B). Se colectaron y analizaron los datos mediante análisis de la varianza (Anova), las comparaciones de medias se realizaron mediante la prueba de Tukey $(\alpha \geq 95 \%)$ con el sistema de análisis estadístico InfoStat Versión 2018e.

\section{Resultados y discusión}

\section{Concentración de carbohidratos en nervaduras y lámina de hoja de limón mexicano}

En la prueba de medias las hojas de árboles de limón Colimex infectados con CLas fueron estadísticamente superiores en concentración de almidón en lámina de hojas de 120 días en comparación con hojas sin HLB. Nervaduras de 30 y 120 días no presentaron diferencias estadísticas entre árboles sanos y enfermos con HLB (Figura 2). En árboles de naranjo dulce infectados con CLas se ha descrito la acumulación de almidón en hojas en comparación con hojas sanas (Rosales y Burns, 2011).

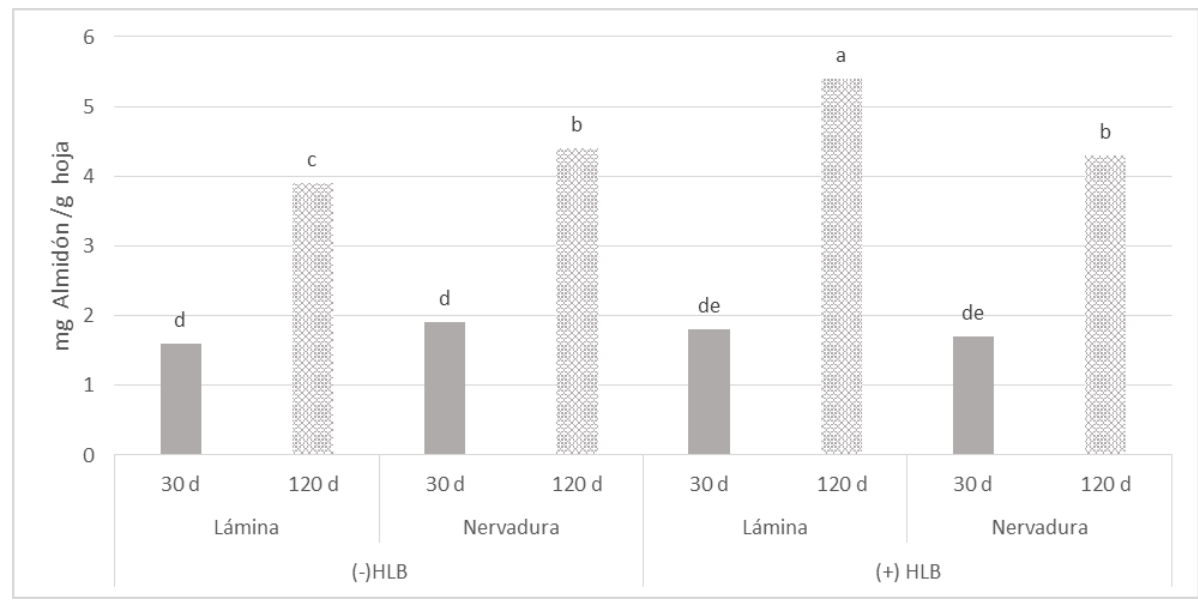

Figura 2. Efecto del CLas en la concentración de almidón en tejido de limón mexicano en producción. Hojas de 30 y 120 días. Sin presencia de HLB (-HLB) e infectadas con HLB (+HLB). Diferentes letras sobre las barras indican diferencias estadísticas significativas $(p<0.05)$. 
Schneider (1968), observó alta acumulación de almidón en hojas y pecíolos en comparación con tejidos sanos. Esta acumulación de almidón es ocasionada por la obstrucción del transporte de fotoasimilados en el sistema vascular foliar y aceleradas tasas de síntesis de almidón en hojas. En naranjos infectadas con HLB, se reportó el taponamiento de tubos cribosos por deposición de calosa (Etxeberria et al., 2009; Kim et al., 2009). La cual tiene un importante papel en la respuesta de defensa de los cítricos al HLB (da Graça et al., 2015), afectando así el transporte de carbohidratos y provocando acumulación masiva de almidón en plastidios de hojas (Schneider, 1968).

También, se ha reportado acumulación de almidón en hoja por deficiencia de Zn (Sagaram y Burns, 2009). Estos resultados concuerdan con Esquivel-Chávez et al. (2012) que encontraron mayor concentración de almidón en hojas de limón mexicano con HLB en invernadero. Sin embargo, el efecto del HLB en la concentración de almidón se observó principalmente en la lámina de hojas de 120 días de limón Colimex en producción, debido a la mayor concentración de cloroplastos en este tejido.

En la Figura 3 se muestra la comparación de medias donde la nervadura de hoja presenta mayor concentración de sacarosa y son estadísticamente diferentes a las láminas foliares en los dos estados de desarrollo evaluados tanto en tejidos infectados como en tejidos sanos. La mayor concentración de sacarosa se presentó en las nervaduras de hojas de 120 días con HLB. En contraste la menor concentración se obtuvo en la lámina foliar de hojas sanas de 30 días. Estos resultados se deben a que CLas causa desequilibrio en el reparto de carbohidratos y acumulación de sacarosa en hoja (Fan et al., 2010).

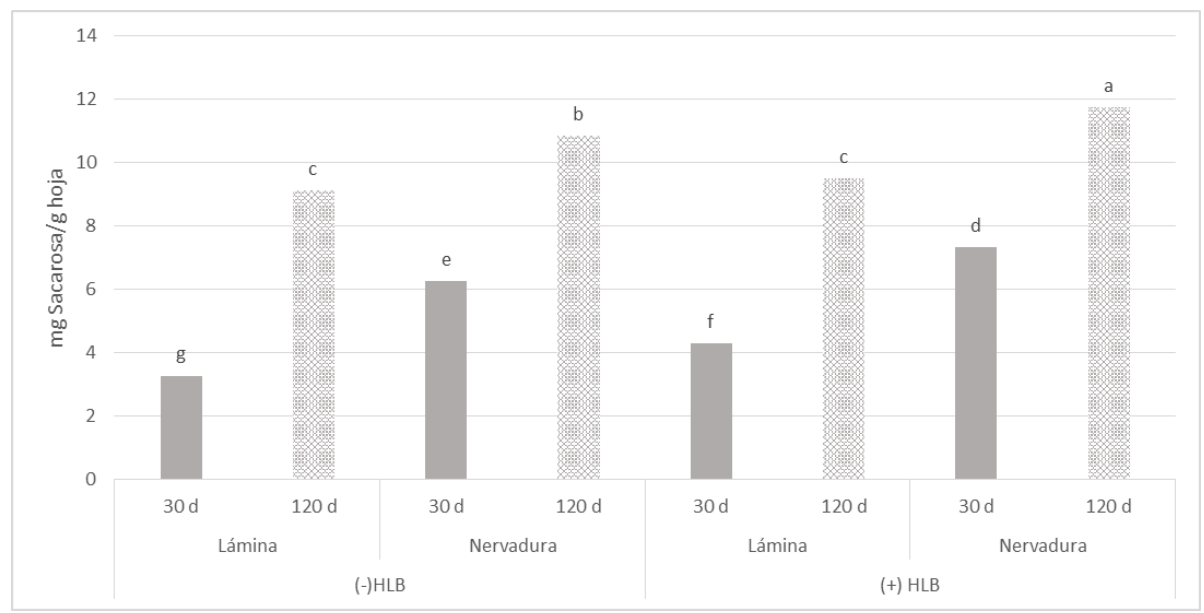

Figura 3. Efecto del CLas en la concentración de sacarosa en tejido de limón mexicano en producción. Hojas de 30 y 120 días. Sin presencia de HLB (-HLB) e infectadas con HLB (+HLB). Diferentes letras sobre las barras indican diferencias estadísticas significativas $(p<0.05)$.

Debido a la concentración de CLas en nervaduras y por la disminución de actividad celular dentro del cambium y el parénquima radial en pecíolos de hojas maduras infectados con HLB, lo que tiene como consecuencia una falla importante en la ruta de transporte de carbohidratos (Brodersen et al., 2014). En limón Colimex con HLB la sacarosa se acumula principalmente en nervaduras de hojas de 120 días. 
Las concentraciones de glucosa en base a la comparación de medias tienen diferencias estadísticas significativas, mostrando mayores concentraciones en tejidos con HLB. Estos resultados muestran la mayor acumulación de glucosa en nervaduras de 30 días con HLB (Figura 4). Esto concuerda con Fan et al. (2010) que describieron que HLB causa desequilibrio en el reparto de carbohidratos y la acumulación glucosa. Debido que CLas se comporta al igual que S. citri, usando fructosa incrementa la actividad de invertasa y por consecuencia acumulan glucosa.

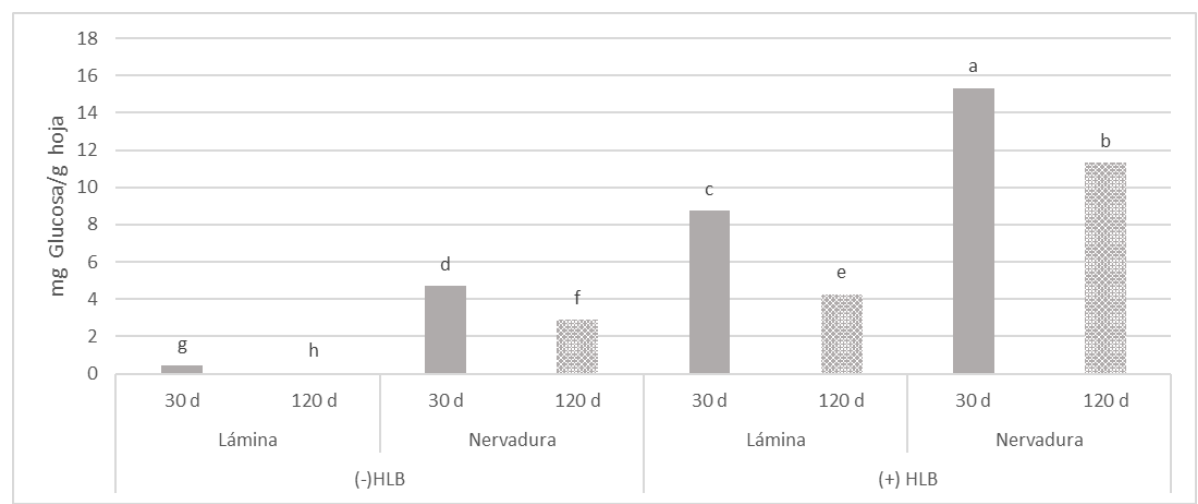

Figura 4. Efecto del CLas en la concentración de glucosa en tejido de limón mexicano en producción. Hojas de 30 y 120 días. Sin presencia de HLB (-HLB) e infectadas con HLB (+HLB). Diferentes letras sobre las barras indican diferencias significativas $(p<0.05)$.

En complemento Li et al. (2009) reportaron mayor concentración de CLas en las nervaduras de hojas infectadas en comparación con la lámina foliar. El HLB causa acumulación de glucosa principalmente en nervadura de 30 días de limón Colimex.

Como se observó en la Figura 5, las raíces de árboles infectados con HLB muestran diferencias estadísticas significativas con las raíces sanas en la concentración de almidón. Con una disminución de 40\%. El limón Colimex presenta disminución en la concentración de almidón en raíces de árboles con HLB. Debido a que sufren un trastorno nutricional por la interrupción del transporte de fotosintatos de los brotes a la raíz (Zhang et al., 2011). Ocasionando disminución de las reservas de almidón en las raíces de árboles infectados con CLas. Lo que también ocasiona que no se desarrollen y supriman el crecimiento de nuevas raíces (Etxeberria et al., 2009).

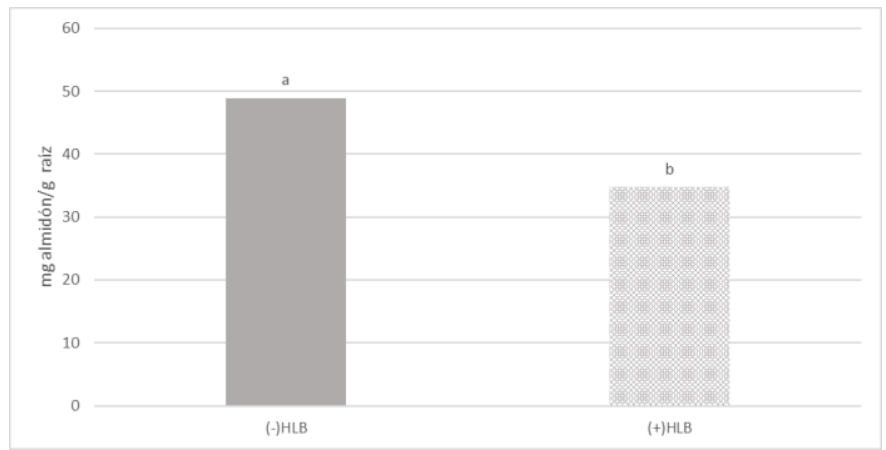

Figura 5. Efecto del CLas en la concentración de almidón en raíces de árboles de limón mexicano en producción. Sin presencia de HLB (-HLB) e infectadas con HLB (+HLB). Diferentes letras sobre las barras indican diferencias significativas $(p<0.05)$. 


\section{Concentración de clorofila en hojas}

Los niveles de afectación desde hojas asintomática hasta el nivel 4 de síntomas de HLB mostraron diferencias estadísticas significativas en la concentración total de clorofila como se muestra en la Figura 6. Debido a la progresiva acumulación de almidones que ocasionan la desintegración del sistema tilacoide del cloroplasto (Etxeberria et al., 2009; González et al., 2011) y daña las membranas fotosintéticas disminuyendo la concentración de clorofila (Sagaram y Burns, 2009). Aunque, el almidón dentro del cloroplasto no rompe las membranas externas, pero la estructura de la grana interna es destruida lo que ocasiona clorosis (Achor $e t$ al., 2010).

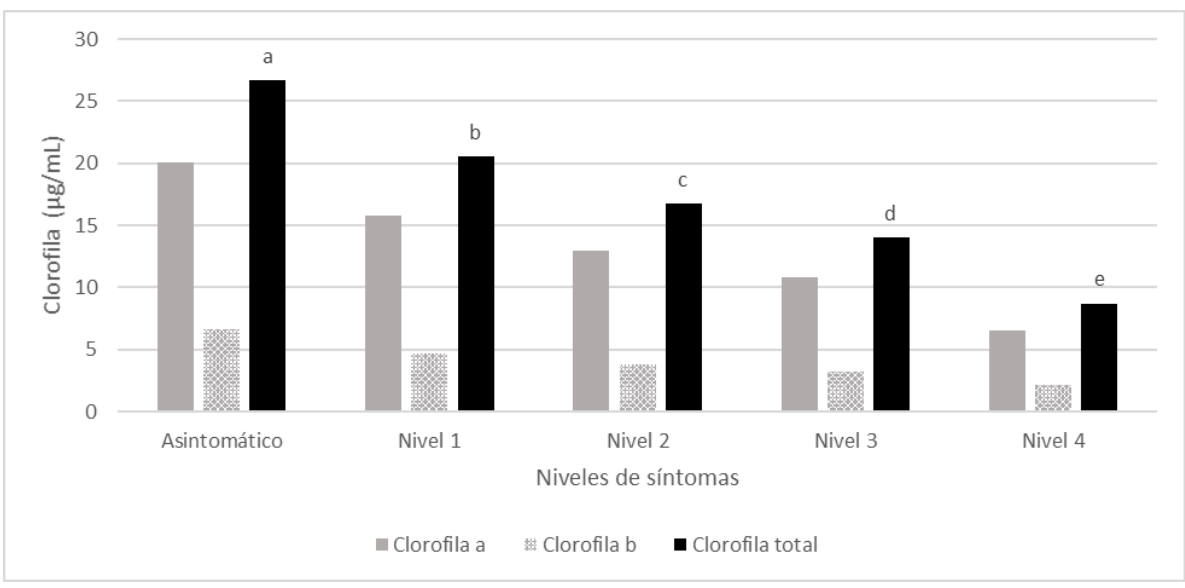

Figura 6. Concentración de clorofila (Clorofila a, Clorofila b y Clorofila total) en hojas de árboles de limón mexicano en producción con diferentes niveles de afectación por HLB. Diferentes letras sobre las barras indican diferencias estadísticas significativas $(p<0.05)$.

También se ha descrito que el aumento de los niveles de sacarosa/glucosa puede llevar a la represión de genes implicados en la fotosíntesis y causar disminución de clorofila (Fan et al., 2010). Por lo que en hojas de limón Colimex se observó la disminución de la concentración de clorofila a, b y total en hoja en función del grado de afectación por HLB.

Al realizar las lecturas SAPD en los niveles de afectación por HLB evaluados, no se encontraron diferencias estadísticas significativas entre las hojas asintomáticas, nivel 1 y nivel 2. En contraste estos fueron diferentes a los niveles 3 y 4 (Figura 7). La lectura SPAD solo es tomada de una parte parcial de la hoja por lo que al no ser uniforme la destrucción de cloroplasto (Achor et al., 2010) el sensor puede captar zonas con diferentes concentraciones de clorofila en la misma hoja.

Por lo que el análisis estadístico solo detecta las diferencias en hojas con marcada clorosis en la mayor parte de la hoja. En limón Colimex el SPAD solo detecta diferencias estadísticas en los grados de mayor afectación por HLB respecto a hojas asintomáticas. 


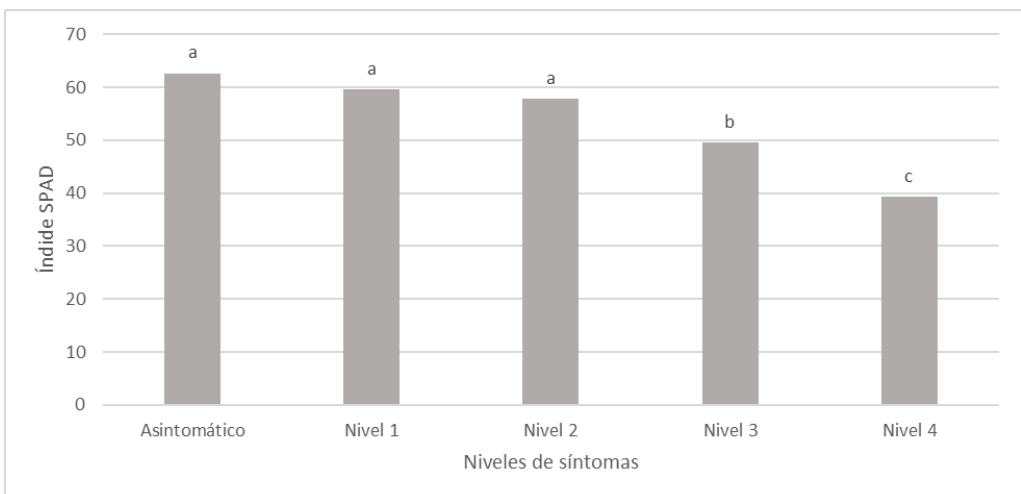

Figura 7. Índice SPAD en hojas de árboles de limón mexicano en producción con diferentes niveles de afectación por HLB. Diferentes letras sobre las barras indican diferencias estadísticas significativas $(p<0.05)$.

\section{Análisis foliar de nutrimentos}

En el Cuadro 1 se presentan los datos de los nutrientes que presentaron diferencias estadísticas significativas entre hojas de árboles con HLB y hojas sanas (potasio, calcio, magnesio, cobre, hierro, zinc y boro) El mismo cuadro muestra el porcentaje de disminución destacando el cobre con más de $57 \%$. El nitrógeno, fósforo y manganeso no presentaron diferencias estadísticas significativas.

Cuadro 1. Efecto de HLB en contenido de nutrientes de hojas de limón mexicano en producción.

\begin{tabular}{cccccccc}
\hline Tratamiento & \multicolumn{1}{c}{$\mathrm{K}\left(\mathrm{mg} \mathrm{g}^{-1}\right)$} & $\mathrm{Ca}\left(\mathrm{mg} \mathrm{g}^{-1}\right)$ & $\mathrm{Mg}\left(\mathrm{mg} \mathrm{g}^{-1}\right)$ & $\mathrm{Cu}\left(\mathrm{mg} \mathrm{kg}^{-1}\right)$ & $\mathrm{Fe}\left(\mathrm{mg} \mathrm{kg}^{-1}\right)$ & $\mathrm{Zn}\left(\mathrm{mg} \mathrm{kg}^{-1}\right) \mathrm{B}\left(\mathrm{mg} \mathrm{kg}^{-1}\right)$ \\
\hline $\begin{array}{c}\text { Colimex } \\
(-\mathrm{HLB})\end{array}$ & $22.37 \mathrm{a}$ & $29.78 \mathrm{a}$ & $0.52 \mathrm{a}$ & $6.72 \mathrm{a}$ & $101.41 \mathrm{a}$ & $33.44 \mathrm{a}$ & $158 \mathrm{a}$ \\
$\begin{array}{c}\text { Colimex } \\
\text { (+HLB })\end{array}$ & $18.83 \mathrm{~b}$ & $25.94 \mathrm{~b}$ & $0.47 \mathrm{~b}$ & $2.85 \mathrm{~b}$ & $66.8 \mathrm{~b}$ & $24.2 \mathrm{~b}$ & $135.06 \mathrm{~b}$ \\
\begin{tabular}{c} 
Reducción \% \\
\hline
\end{tabular} & 15.8 & 12.9 & 9.6 & 57.6 & 34.1 & 27.6 & 14.5 \\
\hline
\end{tabular}

Medias con una letra común no son significativamente diferentes ( $p>0.05)$.

Existen trabajos en varias regiones del mundo con diferentes cítricos que presentan resultados contrastantes. La disminución de Ca y Zn en árboles infectados con HLB. Al igual que Razi et al. (2011) mostraron concentraciones foliares más bajas de Mg y Fe en los árboles con HLB y ninguna diferencia en K, P y Zn. Etxeberria et al. (2009) describieron deficiencias de Zn y Fe en árboles sintomáticos. Al igual que Tian et al. (2014) describen deficiencia de Zn en hojas con HLB. En pomelo infectado con HLB disminuyeron concentraciones de $\mathrm{Ca}, \mathrm{Mg}, \mathrm{Fe}, \mathrm{Zn}, \mathrm{Mn} \mathrm{y} \mathrm{Cu}$. Concordando con este trabajo con excepción del Mn (Nwugo et al., 2013).

El HLB en limón Colimex afecto las concentraciones de $\mathrm{K}, \mathrm{Ca}, \mathrm{Mg}, \mathrm{Cu}, \mathrm{Zn}$ y B debido a la pérdida o restricción de la raíz, que provoca estrés por sequía y cambios en el estatus mineral de los brotes (Spann y Schumann, 2009). Los resultados difieren de lo reportado, por ser diferentes especies y la utilización de contendedores y fertirriego en este experimento. Ya que diferencias en manejo de la nutrición, suelo, clima, combinación variedad/portainjerto, estado de desarrollo de las plantas y la eficiencia de reabsorción de nutrientes durante los experimentos de cítricos infectados con HLB tienen efecto en los datos obtenidos (Razi et al., 2011; Cao et al., 2015). 


\section{Conclusiones}

Debido a la infección de HLB, los árboles de limón mexicano en producción (5 años con la infección) sufren cambios fisiológicos en la distribución y concentración de los carbohidratos, tanto en hoja como en raíz. Así como, disminuye la concentración mineral de $\mathrm{K}, \mathrm{Ca}, \mathrm{Mg}, \mathrm{Cu} \mathrm{Fe} \mathrm{Zn}$ y B. Mientras que a medida que aumentan los síntomas en hoja se reduce la concentración de clorofila. Debido a que este cambio no lleva al colapso de los árboles, es necesario continuar con estudios que permitan conocer y potencializar las rutas que llevan al limón mexicano a continuar su vida productiva a pesar de estar infectados con CLas.

\section{Literatura citada}

Achor, D.; Etxeberria, E.; Wang, N.; Folimonova, S.; Chung, K. and Albrigo, L. 2010. Citrus affected with huanglongbing disease. Plant Pathol. J. 9(2):56-64.

Arratia-Castro, A. A.; Santos-Cervantes, M. E.; Arce-Leal, Á. P.; Espinoza-Mancillas, M. G.; Rodríguez Negrete, E. A.; Méndez-Lozano, J.; Arocha-Rosete, Y. and Leyva-López, N. E. 2016. Detection and quantification of 'Candidatus Phytoplasma asteris' and 'Candidatus Liberibacter asiaticus' at early and late stages of Huanglongbing disease development. Canadian J. Plant Pathol. 38(4):411-421.

Arratia-Castro, A. A.; Santos-Cervantes, M. E.; Fernández-Herrera, E.; Chávez-Medina, J. A.; Flores-Zamora, G. L.; Camacho-Beltrán, E.; Méndez-Lozano, J. and Leyva-López, N. E. 2014. Occurrence of 'Candidatus Phytoplasma asteris' in citrus showing Huanglongbing symptoms in Mexico. Crop Protec. 62(2014):144-151.

Avalos, V. y González, S. 2013. El impacto social, y económico en el comercio del HLB en la cadena de limón mexicano en Colima. In: memorias del IX Simposio Internacional Citrícola. 1 er Simposio internacional sobre HLB en cítricos ácidos. Velázquez-Monreal, J. J. 1-30 pp.

Bové, J. M. 2006. Huanglongbing: a destructive, newly-emerging, century-old disease of citrus. J. Plant Pathol. 88(1):7-37.

Brodersen, C.; Narciso, C.; Reed, M. and Etxeberria, E. 2014. Phloem production in Huanglongbing-affected citrus trees. HortSci. 49(1):59-64.

Cao, J.; Cheng, C.; Yang, J. and Wang, Q. 2015. Pathogen infection drives patterns of nutrient resorption in citrus plants. Scientific reports. 5:14675; doi: 10.1038/srep 14675:1-11.

Cimo, G.; Bianco, R. L.; Gonzalez, P.; Bandaranayake, W.; Etxeberria, E. and Syvertsen, J. P. 2013. Carbohydrate and nutritional responses to stem girdling and drought stress with respect to understanding symptoms of Huanglongbing in citrus. HortSci. 48(7):920-928.

Da Graça, J. and Korsten, L. 2004. Citrus huanglongbing: review, present status and future strategies. In: Diseases of fruits and vegetables volume I. Springer. 229-245 pp.

Da Graça, J.; Kunta, M.; Sétamou, M.; Rascoe, J.; Li, W.; Nakhla, M.; Salas, B. and Bartels, D. 2015. Huanglongbing in Texas: Report on the first detections in commercial citrus. J. Citrus Pathol. 2(1):1-6.

Duan, Y.; Zhou, L.; Hall, D. G.; Li, W.; Doddapaneni, H.; Lin, H.; Liu, L.; Vahling, C. M.; Gabriel, D. W. and Williams, K. P. 2009. Complete genome sequence of citrus huanglongbing bacterium, 'Candidatus Liberibacter asiaticus' obtained through metagenomics. Mol. PlantMicrobe Inter. 22(8):1011-1020. 
Esquivel-Chávez, F.; Valdovinos-Ponce, G.; Mora-Aguilera, G.; Gómez-Jaimes, R.; VelázquezMonreal, J. J.; Manzanilla-Ramírez, M. Á.; Flores-Sánchez, J. L. and López-Arroyo, J. I. 2012. Análisis histológico foliar de cítricos agrios y naranja dulce con síntomas ocasionados por Candidatus Liberibacter asiaticus. Agrociencia. 46(8):769-782.

Etxeberria, E.; Gonzalez, P.; Achor, D. and Albrigo, G. 2009. Anatomical distribution of abnormally high levels of starch in HLB-affected Valencia orange trees. Physiol. Mol. Plant Pathol. 74(1):76-83.

Fan, J.; Chen, C.; Brlansky, R.; Gmitter Jr, F. and Li, Z. G. 2010. Changes in carbohydrate metabolism in Citrus sinensis infected with 'Candidatus Liberibacter asiaticus'. Plant Pathol. 59(6):1037-1043.

Garnier, M. and Bové, J. 1996. Distribution of the huanglongbing (greening) Liberobacter species in fifteen African and Asian countries. In: International Organization of Citrus Virologists Conference Proceedings. 13(13):388-391.

Gonzalez, P.; Reyes, J. and Etxeberria, E. 2011. Starch analysis of HLB-affected and control healthy citrus leaves reveal variations in the amylose/amylopectin ratio. In: Proc. Fla. State Hort. Soc. 124:69-75.

Gonzalez, P.; Reyes-De-Corcuera, J. and Etxeberria, E. 2012. Characterization of leaf starch from HLB-affected and unaffected-girdled citrus trees. Physiol. Mol. Plant Pathol. 79:71-78.

Hijaz, F. and Killiny, N. 2014. Collection and chemical composition of phloem sap from Citrus sinensis L. Osbeck (sweet orange). PloS one 9(7), e101830.

Intrigliolo, F.; Giuffrida, A.; Rapisarda, P.; Calabretta, M. and Roccuzzo, G. 2000. SPAD as an indicator of nitrogen status in Citrus. In: proceeding of the IXth international citrus congress, Orlando, FL. 665-667 pp.

Jagoueix, S.; Bove, J.-m. and Garnier, M. 1994. The phloem-limited bacterium of greening disease of citrus is a member of the $\alpha$ subdivision of the Proteobacteria. Inter. J. System. Evol. Microbiol. 44(3):379-386.

Kim, J.-S.; Sagaram, U. S.; Burns, J. K.; Li, J.-L. and Wang, N. 2009. Response of sweet orange (Citrus sinensis) to 'Candidatus Liberibacter asiaticus' infection: microscopy and microarray analyses. Phytopathology. 99(1):50-57.

Koh, E.-J.; Zhou, L.; Williams, D. S.; Park, J.; Ding, N.; Duan, Y.-P. and Kang, B.-H. 2012. Callose deposition in the phloem plasmodesmata and inhibition of phloem transport in citrus leaves infected with 'Candidatus Liberibacter asiaticus'. Protoplasma. 249(3):687-697.

Li, W.; Hartung, J. S. and Levy, L. 2006. Quantitative real-time PCR for detection and identification of Candidatus Liberibacter species associated with citrus huanglongbing. Journal of microbiological methods. 66(1):104-115.

Li, W.; Levy, L. and Hartung, J. S. 2009. Quantitative distribution of 'Candidatus Liberibacter asiaticus' in citrus plants with citrus huanglongbing. Phytopathology. 99(2):139-144.

Mann, R. S.; Ali, J. G.; Hermann, S. L.; Tiwari, S.; Pelz-Stelinski, K. S.; Alborn, H. T. and Stelinski, L. L. 2012. Induced release of a plant-defense volatile 'deceptively'attracts insect vectors to plants infected with a bacterial pathogen. PLoS pathogens 8, e1002610.

Manzanilla-Ramírez, M. Á.; Velázquez-Monreal, J. J.; Bermúdez-Guzmán, M. D. J.; GarcíaMariscal, K. D. 1. P.; Orozco-Santos, M. y Robles-González, M. M. 2018. Manejo integral del cultivo de limón mexicano en un escenario de alta incidencia de HLB. Folleto. INIFAP. $26 \mathrm{p}$.

Munir, S.; He, P.; Wu, Y.; He, P.; Khan, S.; Huang, M.; Cui, W.; He, P. and He, Y. 2017. Huanglongbing control: perhaps the end of the beginning. Microbial Ecol. 76(1):192-204. 
Nwugo, C. C.; Duan, Y. and Lin, H. 2013. Study on citrus response to huanglongbing highlights a down-regulation of defense-related proteins in lemon plants upon 'Ca. Liberibacter asiaticus' infection. PloS one 8, e67442.

Pereira, F. M. V. and Milori, D. M. B. P. 2010. Investigation of the stages of citrus greening disease using micro synchrotron radiation X-ray fluorescence in association with chemometric tools. J. Analy. Atomic Spectrom. 25(3):351-355.

Razi, M.; Khan, I. A. and Jaskani, M. J. 2011. Citrus plant nutritional profile in relation to Huanglongbing prevalence in Pakistan. Pak. J. Agric. Sci. 48(4):299-304.

Robles-González, M. M.; Orozco-Santos, M.; Manzanilla-Ramírez, M. Á.; Velázquez-Monreal, J. J. y Carrillo-Medrano, S. H. 2017. Efecto del HLB sobre el rendimiento de limón mexicano en Colima, México. Rev. Mex. Cienc. Agríc. 8(5):1101-1111.

Robles-González, M. M.; Velázquez-Monreal, J. J.; Manzanilla-Ramirez, M. Á.; Orozco-Santos, M.; Medina-Urrutia, V. M.; López-Arroyo, J. I. y Flores-Virgen, R. 2013. Síntomas del Huanglongbing HLB en árboles de limón mexicano [Citrus aurantifolia (Christm) Swingle] y su dispersión en el estado de Colima, México. Rev. Chapingo Ser. Hortic. 19(1):15-31.

Rosales, R. and Burns, J. K. 2011. Phytohormone changes and carbohydrate status in sweet orange fruit from Huanglongbing-infected trees. J. Plant Growth Reg. 30(3):312-321.

Sagaram, M. and Burns, J. K. 2009. Leaf chlorophyll fluorescence parameters and huanglongbing. J. Am. Soc. Hortic. Sci. 134(2):194-201.

Schneider, H. 1968. Anatomy of greening-diseased sweet orange shoots. Phytopathology. 58(1):1155-1160.

Spann, T. M. and Schumann, A. W. 2009. The role of plant nutrients in disease development with emphasis on citrus and huanglongbing. In: Proc. Fla. State Hort. Soc. 122:169-171.

Spann, T. M.; Schumann, A. W.; Rouse, B. and Ebel, B. 2011. Foliar nutrition for HLB. Citrus Industry. 92(6):6-10.

Tian, S.; Lu, L.; Labavitch, J. M.; Webb, S. M.; Yang, X.; Brown, P. H. and He, Z. 2014. Spatial imaging of $\mathrm{Zn}$ and other elements in Huanglongbing-affected grapefruit by synchrotronbased micro X-ray fluorescence investigation. J. Exp. Bot. 65(4):953-964.

Warren, C. 2008. Rapid measurement of chlorophylls with a microplate reader. J. Plant Nutr. 31(7):1321-1332.

Zhang, M.; Powell, C. A.; Zhou, L.; He, Z.; Stover, E. and Duan, Y. 2011. Chemical compounds effective against the citrus Huanglongbing bacterium 'Candidatus Liberibacter asiaticus' in planta. Phytopathology. 101(9):1097-1103. 